Int. J. Electrochem. Sci., 16 (2021) Article ID: 210770

International Journal of

ELECTROCHEMICAL

SCIENCE

$\underline{\text { www.electrochemsci.org }}$

\title{
The inhibition effect of eco-friendly sodium dodecyl sulfate on the corrosion behavior of SUS304L, SUS304H, and SUS316H stainless steels in sulfuric acid solution
}

\author{
Magdy A.M. Ibrahim ${ }^{1, *}$, Mossad M. Hamza ${ }^{1}$, Jacek Ryl, , Mohammed A. Amin ${ }^{3, *}$, Sayed S. Abd El \\ Rehim $^{1}$ \\ ${ }^{1}$ Faculty of Science, Chemistry Department, Ain Shams University, Cairo 11566, Egypt \\ ${ }^{2}$ Institute of Nanotechnology and Materials Engineering, Faculty of Applied Physics and Mathematics, \\ Gdansk University of Technology, Narutowicza 11/12, 80-233 Gdansk, Poland \\ ${ }^{3}$ Department of chemistry, College of Science, Taif University, P.O. Box 11099, Taif 21944, Saudi \\ Arabia \\ *E-mail: imagdy1963@hotmail.com
}

doi: $10.20964 / 2021.07 .21$

Received: 28 February 2021 / Accepted: 24 April 2021 / Published: 31 May 2021

The inhibition characteristics of an anionic surfactant, sodium dodecyl sulfate (SDS), against the corrosion of SUS304L, SUS304H, and SUS316H stainless steels in $0.5 \mathrm{M}$ sulfuric acid were assessed utilizing Tafel extrapolation and electrochemical impedance spectroscopy (EIS) methods. The investigated surfactant behaved as a mixed-type inhibitor in all cases, as reported by the results of polarization measurements. For all stainless steel tested, the inhibition efficacy ( $\eta \%)$ improved as the SDS concentration enhanced, attaining its maximum value at the SDS's critical micelle concentration (CMC). At a given $C_{\mathrm{SDS}}$, in all cases, the $\eta \%$ values are found to decline with raising temperature referring to the physisorption of the inhibitors' molecules. The sulfuric acid corrosion of the three stainless steels tested was significantly reduced by the SDS molecules via adsorption following the Temkin adsorption isotherm. The stability and durability of such inhibitor molecules' adsorbed protective films were studied using EIS performed at various submerging periods (5-120 min). The outcomes of the polarization and impedance measurements are very similar. The various standard thermodynamic functions for the inhibitor molecules' adsorption process, namely $\Delta \mathrm{G}^{\mathrm{o}}{ }_{\mathrm{ads}}, \Delta \mathrm{H}^{\mathrm{o}}{ }_{\mathrm{a}}$ and $\Delta \mathrm{S}_{\mathrm{a}}^{\mathrm{o}}$ were estimated and discussed.

Keywords: Adsorption isotherm; Sodium dodecyl sulfate; Stainless steel; Tafel extrapolation method; EIS.

\section{FULL TEXT}


(C) 2021 The Authors. Published by ESG (www.electrochemsci.org). This article is an open access article distributed under the terms and conditions of the Creative Commons Attribution license (http://creativecommons.org/licenses/by/4.0/). 